\title{
Investigation of elemental distribution in cat femoral head by nuclear microprobe and SEM for Paget disease of bone studies
}

\author{
C. Santos***, M. Fonseca****, V. Corregidor*****, L.C. Alves******, H. Luis***, M. Capelão****, J.C. \\ Branco*****, P.A Carvalho****** and A.P. Jesus****
}

*Departamento de Física, Faculdade de Ciências e Tecnologia, Universidade Nova de Lisboa, 2829-516 Caparica, Portugal

**Centro de Física Nuclear da Universidade de Lisboa, 1649-003 Lisboa, Portugal

***Campus Tecnológico e Nuclear, IST/ITN, Universidade de Lisboa E.N. 10, 2686-953 Sacavém

****Hospital Veterinário do Restelo, Rua Gregório Lopes Lote 1513 - Loja E 1400-195 Lisboa, Portugal

*****CEDOC, Faculdade de Ciências Médicas da Universidade Nova de Lisboa. Campo Mártires da Pátria, 1169-056 Lisboa

******ICEMS, Instituto Superior Técnico, Universidade de Lisboa, Av. Rovisco Pais, 1049-001 Lisboa, Portugal

Paget Disease of Bone is a disorder characterized by abnormal bone remodeling, associated with morphological and functional abnormalities of osteoclasts although its etiology remains unproven [1]. Ion beam analysis (IBA) techniques may be useful to characterize the abnormal distribution and concentration of the major and trace elements that can be associated topagetic bone condition. In order to access the viability of this approach, healthy femoral head of cat has been investigated by Particle Induced X-Ray Emission (PIXE),Rutherford Backscattering Spectrometry (RBS) and Scanning Electron Microscopy (SEM).

The bone section was irradiated, under vacuum conditions, with a $2.0 \mathrm{MeV}$ alpha particle beam produced by the 2.5 MV Van de Graaff Accelerator of CTN/IST (Lisbon, Portugal). An Oxford Microbeams-type nuclear microprobe was used (OM150 triplet system) [2], which allowed the proton beam to be focused on the bone section with a spatial resolution of $3 \times 4 \mu^{2}$ and a mean beam current of $\sim 90 \mathrm{pA}$. The X-rays generated by the bone were recorded using an $80 \mathrm{~mm}^{2}$ Link X-ray detector (with a $145 \mathrm{eV}$ energy resolution), that is positioned at $135^{\circ}$ to the beam direction. The backscattered particles were collected by a $200 \mathrm{~mm}^{2}$ silicon surface barrier radiation detector with a $15 \mathrm{keV}$ energy resolution that is positioned at $40^{\circ}$ to the beam direction in a cornell geometry. SEM observations have been carried out with backscattered electrons (BSE) using a JEOL JSM 7001F microscope equipped with an INCA Oxford Instruments EDS spectrometer for point analyses and X-ray mapping. Standard petrographic procedures have been employed to prepare the samples for SEM observation: the specimens were partly encapsulated in epoxy resin, ground with 800 and 1000-grit SiC paper, polished with $6 \mu \mathrm{m}$ and $1 \mu \mathrm{m}$ diamond suspensions and coated with carbon.

A selected area of the sample has been scanned with the proton beam, allowing to generateelemental distribution maps for $\mathrm{Ca}$ and $\mathrm{P}$ (Figure 1). From X-line scans it was possible to extractline profiles of these elements. RBS and PIXE were used to determine the matrix and trace element composition in order to normalize the elemental concentrations. The results are shown in Table 1.Structural information on the Haversian Systems, includingbone lacunaeandosteocytes localization have been obtained by SEM (Figure 2).

The combination of these techniques proved to be a viable approach for the Pagetic bone characterization and will be used to analyze the structure of trabecular and cortical bones as well as the distribution and morphology of the pagetic bone cells, which can contribute to clarify the differences between pagetic and healthy bone.

\section{References}

1. Siris E.S., Journal of bone and Mineral Research, 13:1061-1065, 1998.

2. Alves L.C. et al., NIMB, 161:334-338, 2000. 


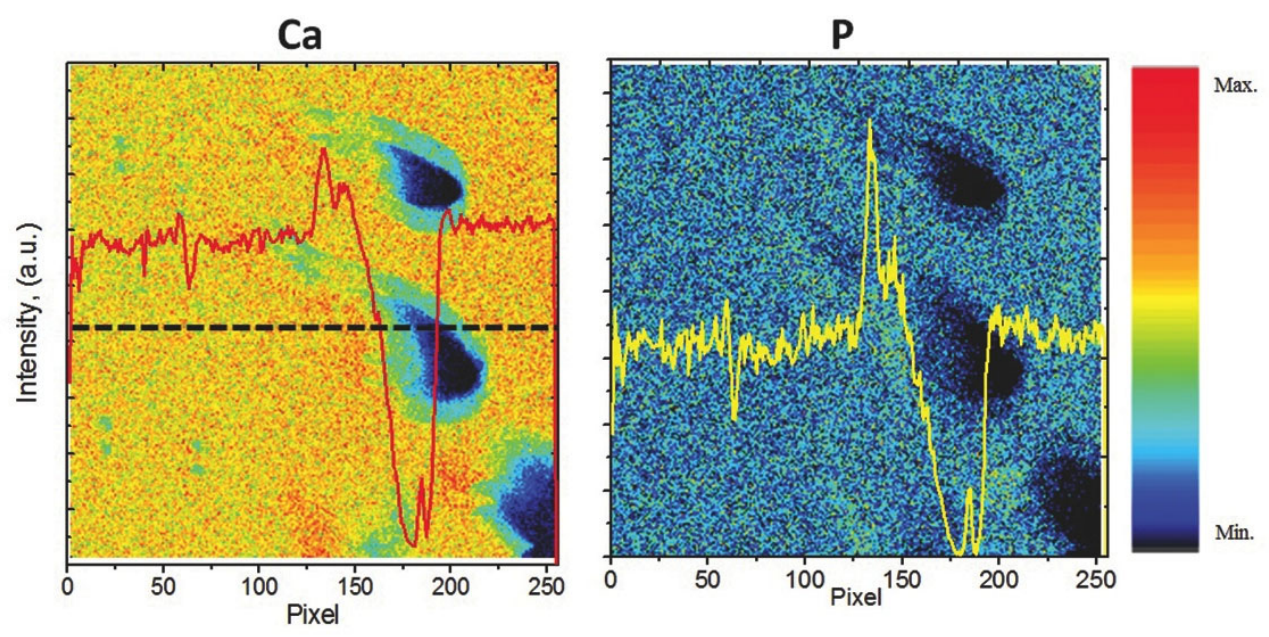

Figure 1 - 2D Elemental distribution of Ca (left side) and P (right side) along the bone section (1320x1320 $\mu \mathrm{m}^{2}$ ) and line profiles of these elements along the black line indicated at the elemental distribution.

\begin{tabular}{|c|c|c|}
\hline Element & $\begin{array}{c}\text { PIXE } \\
\left(10^{15} \text { atoms } / \mathrm{cm}^{2}\right)\end{array}$ & $\begin{array}{c}\text { RBS } \\
\left(10^{15} \text { atoms } / \mathrm{cm}^{2}\right)\end{array}$ \\
\hline Al & $6.7 \mathrm{E}-03$ & $6.5 \mathrm{E}-03$ \\
\hline $\mathbf{S i}$ & $1.4 \mathrm{E}-03$ & $1.4 \mathrm{E}-03$ \\
\hline $\mathbf{P}$ & $1.3 \mathrm{E}-02$ & $1.3 \mathrm{E}-02$ \\
\hline $\mathbf{S}$ & $9.2 \mathrm{E}-05$ & $1.0 \mathrm{E}-04$ \\
\hline Cl & $2.3 \mathrm{E}-05$ & $2.0 \mathrm{E}-05$ \\
\hline $\mathbf{K}$ & $1.0 \mathrm{E}-04$ & $1.0 \mathrm{E}-04$ \\
\hline $\mathrm{Ca}$ & $3.1 \mathrm{E}-02$ & $3.0 \mathrm{E}-02$ \\
\hline
\end{tabular}

Table 1 - Elemental concentration of the cat femoral head obtained by PIXE and RBS.

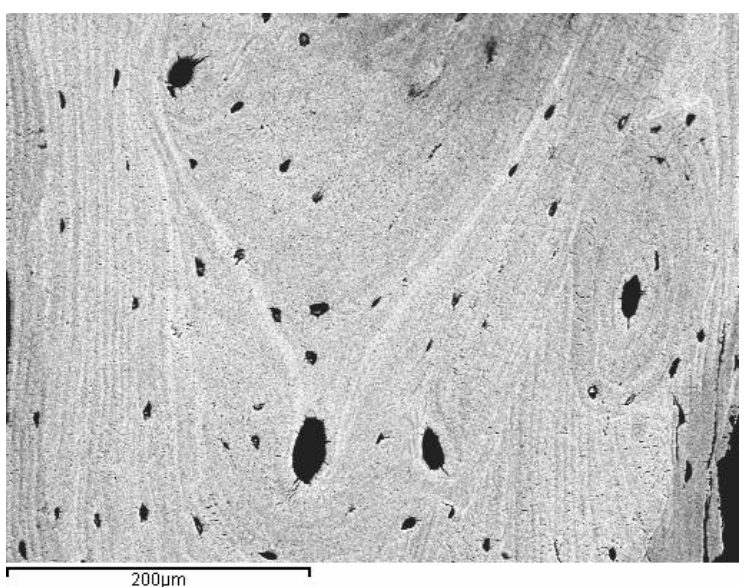

Figure 2 - SEM image of the cat femoral.

V. Corregidor acknowledges the support from FCT-Ciência program. The work was also supported by FCT PEST-OE/CTM-UI0084/2011 grant. 